\title{
Effect of Acetylation on Stability to Retrogradation of Starch Extracted from Wild Polynesian Arrowroot (Tacca leontopetaloides (L.) Kuntze) for Utilization as Adhesive on Paper
}

\author{
Hamza Abba, ${ }^{1}$ Abdulqadir Ibrahim, ${ }^{2}$ Gideon A. Shallangwa, ${ }^{1}$ \\ Sani Uba, ${ }^{1}$ and Yakubu A. Dallatu ${ }^{1}$ \\ ${ }^{1}$ Department of Chemistry, Ahmadu Bello University, P.M.B.1045, Zaria 810006, Nigeria \\ ${ }^{2}$ Department of Chemistry, Nigeria Police Academy, P.M.B.3474, Wudil, Kano State 713212, Nigeria \\ Correspondence should be addressed to Hamza Abba; hamzaabbah@yahoo.com
}

Received 22 November 2013; Revised 24 January 2014; Accepted 2 February 2014; Published 13 March 2014

Academic Editor: Cornelia Vasile

Copyright (c) 2014 Hamza Abba et al. This is an open access article distributed under the Creative Commons Attribution License, which permits unrestricted use, distribution, and reproduction in any medium, provided the original work is properly cited.

\begin{abstract}
Starch was isolated from T. leontopetaloides tubers, chemically modified by acetylation with varying amounts of acetic anhydride. Monolayer of the ten acetylated and control starch powders was exposed on roof top for five weeks and pastes of both exposed and unexposed (control) samples were prepared with distilled water $(1: 3 \mathrm{w} / \mathrm{w})$. The effects of acetylation, degree of substitution (DS), and exposure to sunlight were investigated to evaluate the retrogradation tendency of the adhesive pastes from changes in syneresis, tack strength, optical clarity, viscosity, gelation time, and drying time. The results obtained showed that all the adhesive properties studied were affected by both DS and exposure to sunlight. While tack strength, viscosity, and drying time were found to increase with increase in DS, syneresis, optical clarity, and gelation time were found to decrease with increase in DS. Increase in tack strength and reduction in syneresis imply that the acetylation treatment has made T. leontopetaloides starch more suitable for use in remoistenable adhesive applications. The reduction in syneresis, optical clarity, and gelation time with increase in DS was attributed to the strengthening of the bonds between the amylose and amylopectin molecules, preventing water leaching out of the starch granules.
\end{abstract}

\section{Introduction}

Adhesive is a natural or synthetic substance that, when applied to surfaces of materials, binds them and the joint resist separation. Natural bioadhesives are obtained from vegetable matter, starch, plant exudates, and resins or from animals, for example, casein [1-5]. Advantages of adhesives over other binding techniques include ability to bind different materials together, efficient distribution of stress across the bonded joint, cost effectiveness, easy process mechanization, improvement in aesthetics design, and design flexibility [69].

Starch, $\left(\mathrm{C}_{6} \mathrm{H}_{10} \mathrm{O}_{5}\right)_{n}$, is a complex carbohydrate occurring in the form of minute granules in seeds, fruits, tubers, roots, and stem pith of plants, consisting of two polymers, amylose and amylopectin, and the molar ratio of which is about 20 $30 \%$ and $80-70 \%$, respectively [10-13]. Amylose is a linear polysaccharide composed of mostly linear chains with 500$20,000 \alpha$-( $1 \rightarrow 4)$-D-glucose units, as can be seen in Figure 1 $[14,15]$.

Depending on the botanic source, amylose can form an extended shape (hydrodynamic radius $7-22 \mathrm{~nm}$ ) but generally tends to wind up into a rather stiff left-handed single helix or form even stiffer parallel left-handed double helical junction zones [16]. Single helical amylose has hydrogenbonding $\mathrm{O} 2$ and $\mathrm{O} 6$ atoms on outside surface of the helix with only the ring oxygen pointing inwards [17-19].

Amylopectin molecule consists of both crystalline $(\sim 30 \%)$ and amorphous areas containing up to two million glucose residues oriented radially in a compact structure 


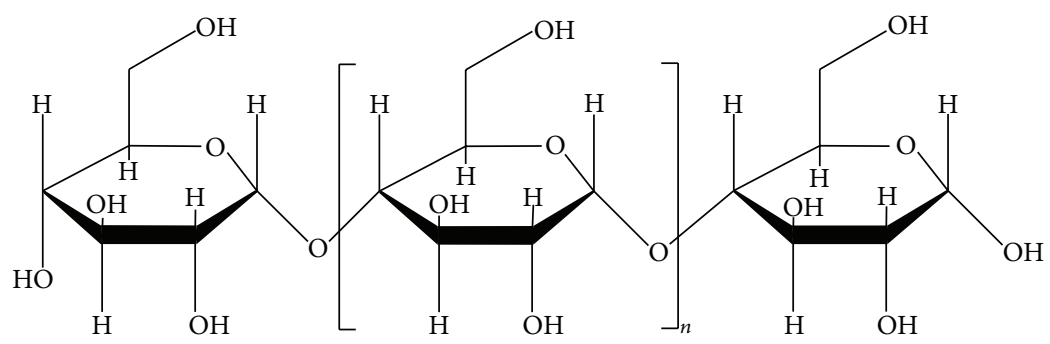

FIgURE 1: Amylose molecule (adapted from Ward et al. [19]).

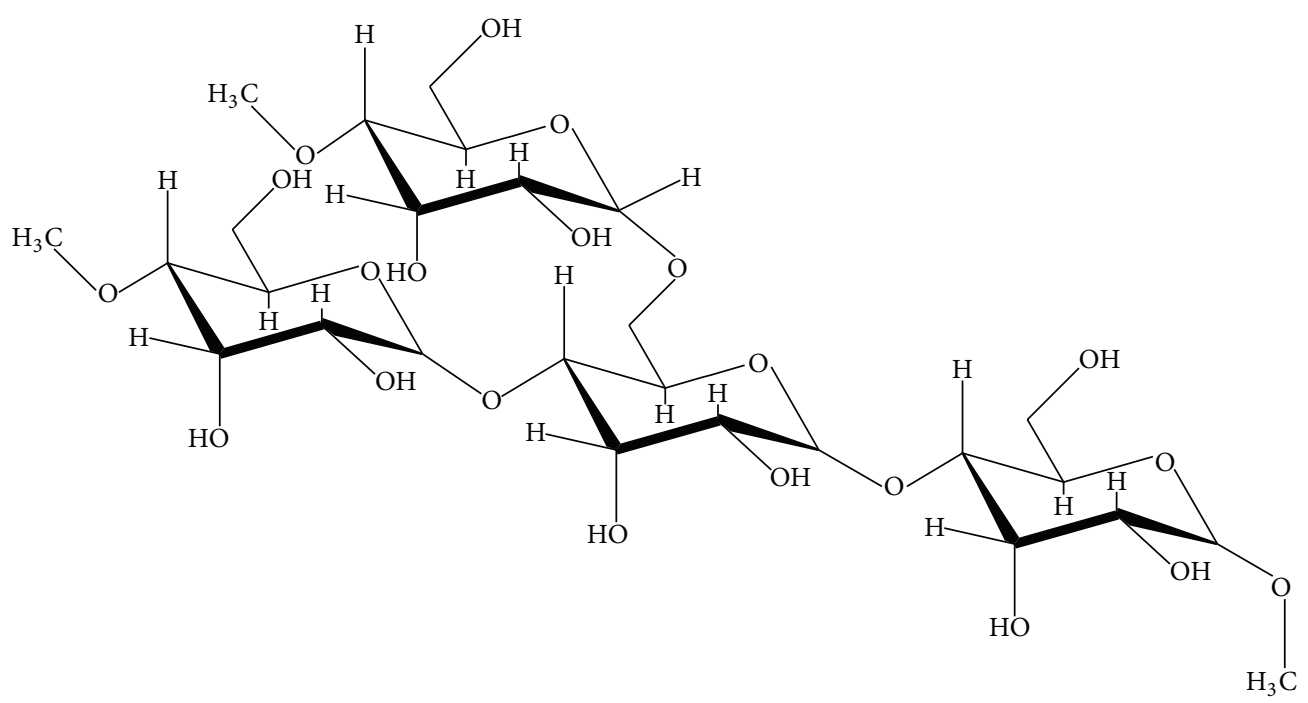

FIgURE 2: Amylopectin molecule (adapted from Tako and Hizukuri [20]).

(Figure 2) having hydrodynamic radius $21-75 \mathrm{~nm}$ with the radius increasing as the number of branches required to fill up the space, with the consequent formation of concentric regions of alternating amorphous and crystalline structure [20-22].

Economic and technological advancements of nations are tied to raw materials research and development, especially from waste agricultural resources [23, 24]. Industrially, starch is used because of its adhesive, film-forming, gelling, and thickening properties. Unfortunately, retrogradation (a reaction that takes place in gelatinized starch when the polymer chains realign themselves and begin to reassociate into a well-organized structure, causing the liquid to gel) limits these properties as most native starches do not have the functional properties required to impart or maintain desired qualities [25-27]. There are several reports from the literature that retrogradation consists of three stages: starch granules was swelled and melted with loss of X-ray crystallinity and formation of both crystalline and amorphous lamellae; secondly, in crystalline lamellae, amylopectin began to form nucleation when they were autoclaved; finally, the nucleus grew up to great rod-like crystals as the result of congregating of amylose on plates which were composed of and prolonged by amylopectin [28-32]. Charoenrein and coworkers have, in two separate studies, reported that retrogradation manifests in expulsion liquid from the polymer network (syneresis) with the "weeping" jelly squeezing water out of the gel network caused by a warm storage place, fluctuated storage temperature and prolonged storage [33, 34]. Other signs of retrogradation are increase in opacity [35], reduction in tack strength [36], cold water insolubility [37], thermal instability [38], and shorter shelf life [39] of starch-based adhesive systems on ageing. Fortunately, native starches can be modified biotechnologically [40, 41], chemically [42-46], or physically [47-51] to overcome these shortcomings.

Acetylation (IUPAC ethanoylation) describes a reaction that introduces acetyl $\left(\mathrm{CH}_{3} \mathrm{CO}\right)$ functional group to replace the hydrogen atom in alcohols and amines [52]. Acetic anhydride $\left[\left(\mathrm{CH}_{3} \mathrm{CO}\right)_{2} \mathrm{O}\right]$ is a clear, colorless, and mobile (freeflowing) liquid used as solvent for many organic compounds. It is also used in the manufacture of industrial chemicals, pharmaceuticals, perfumes, plastics, synthetic fibers, explosives, and weed killers [53]. It was reported that about 75 percent of the acetic anhydride produced annually in the United States is used in the manufacture of cellulose acetate for films and plastic goods [54]. Acetylation (esterification) is the most widely used chemical method of modifying starch to improve its properties and extend the industrial application range of its products. The acetylation process used in the synthesis of acetylated starch by the reaction 


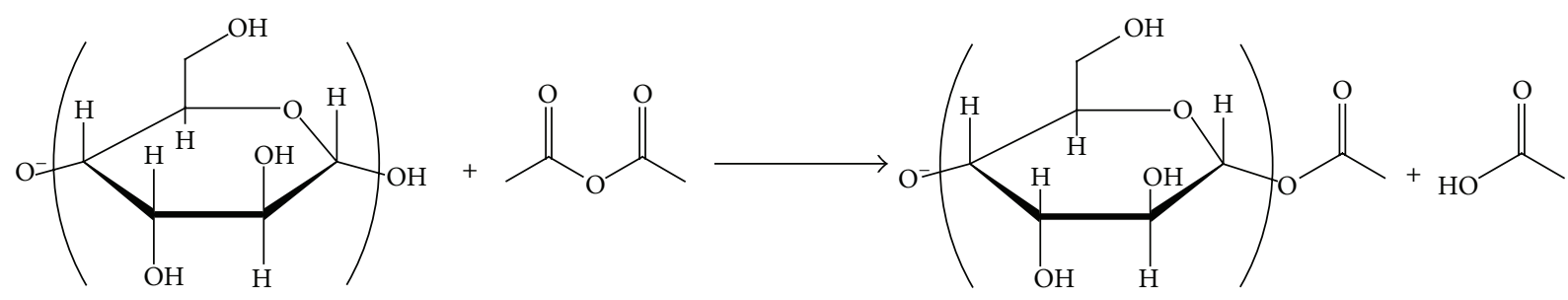

Scheme 1: Acetylation of an anhydroglucose unit of a starch polymer with acetic anhydride.

of native corn starch with acetic anhydride was reported to be a substitution reaction that takes place by an additionelimination mechanism as shown in Scheme $1[55,56]$.

It has been reported severally that, although it has many species, the family Taccaceae consists of only one living genus, Tacca [57-59]. Polynesian arrowroot [Tacca leontopetaloides (L.) Kuntze 1891] that is native to Tropical Africa, South Asia, Southeast Asia, Northern Australia, New Guinea, Samoa, Micronesia, and Fiji [60]. In Nigeria, the large tuberous perennial terrestrial herb grows wild during the humid seasons in Northern Nigerian, especially Kaduna and Niger states [61, 62]. Although many environmental factors were reported by several workers to affect performance of adhesives, sunlight is the most serious agency [63-65].

The aim of this study was to extract starch from the wild Tacca leontopetaloides, add varying amounts of acetic anhydride to it, investigate the effects of degree of substitution and exposure to sunlight, and assess the suitability of the acetylated starch for remoistenable adhesive use in postage stamps, envelope flaps, labels, and other paper fastening works.

\section{Materials and Methods}

The T. leontopetaloides tubers used in this study were collected from Dumbi village, along Zaria-Kaduna highway, Kaduna state, Nigeria. $\left(\mathrm{CH}_{3} \mathrm{CO}\right)_{2} \mathrm{O}, \mathrm{NaOH}$, and $\mathrm{HCl}$ were analytical grade reagents from $\mathrm{BDH}$, England, and were used as received.

2.1. Isolation of Starch. The fresh T. leontopetaloides tubers were washed, peeled, cut into small chips, and homogenized in a Phillips blender with minimal amount of water. The slurry was mixed with five times its volume of water and sieved with a muslin cloth. The starch slurry was allowed to settle, the supernatant decanted and the settled starch washed several times with distilled water. The resultant white starch was air-dried and further oven-dried at $105^{\circ} \mathrm{C}$ to constant weight. The dried crude starch powder was then stored in a sealed plastic container before use.

2.2. Acetylation of the Native Starch. Starch (162 g) was placed into $400 \mathrm{~mL}$ beaker and $220 \mathrm{~mL}$ of distilled water and the mixture was stirred for $30 \mathrm{~min}$. The $\mathrm{pH}$ of the slurry was adjusted to 8.0 with $3 \% \mathrm{NaOH}$. Acetic anhydride $(2.55 \mathrm{~g}$ ) was slowly added to the starch suspension (in agitation) and the reaction was allowed to proceed for $15 \mathrm{~min}$. Thereafter, the $\mathrm{pH}$ was adjusted to 4.5 with $0.5 \mathrm{M} \mathrm{HCl}$ and the slurry filtered on a Buchner funnel containing Whatman No. 4. The residue obtained was washed with distilled water to completely remove any impurities and the product was finally air-dried at room temperature $\left(33^{\circ} \mathrm{C}\right)$. The acetylation experiment was repeated by adding $5.10,7.65,11.20,13.75,16.30,18.85,21.40$, 23.95 , and $26.50 \mathrm{~g}$ of the acetic anhydride. The percentage of acetyl content, the degree of substitution (DS), and the reaction efficiency (RE) for each of the 10 acetylated samples were calculated following a standard method [66]. The eleven samples (control and acetylated) were divided into two sets; one set was exposed outdoors for five weeks and the other set was kept at room temperature in the dark.

2.3. Exposure to Sunlight. Standardmethod of natural outdoor ageing (weathering) of adhesives to sunlight was followed [67]. Each of the 11 samples ( $50 \mathrm{~g}$ ) was evenly sprayed in a ceramic crucible; the crucible mounted on a wooden rack frame and exposed rooftop at $45^{\circ}$ angle (Slant Exposure) facing south for five weeks, with average room temperature being $33^{\circ} \mathrm{C}$.

2.4. Preparation of Starch Pastes. Each of the 11 samples (50 g), exposed and unexposed, was dispersed into $45 \mathrm{~mL}$ distilled water in a $100 \mathrm{~mL}$ beaker. The slurry obtained was homogenized, placed in a tube, sealed, and centrifuged at $1500 \mathrm{rpm}$ to remove the excess water.

2.5. Determination of Syneresis. Freeze-thaw stability, a measure of syneresis, of both exposed and unexposed samples, was determined by slightly modifying a method reported in the literature [34]. Native and acetylated starch (3.0 g, dry weight) was suspended in distilled water $(100 \mathrm{~mL})$ in a screw cap tube and boiled for $20 \mathrm{~min}$. After cooling to room temperature $\left(33^{\circ} \mathrm{C}\right)$, each paste was divided into four equal parts and transferred to four centrifuge tubes. The four samples were kept refrigerated at $-20^{\circ} \mathrm{C}$ for $24 \mathrm{~h}$ and then thawed at $33^{\circ} \mathrm{C}$ for $6 \mathrm{~h}$. Each of the four tubes was then centrifuged in a L-550 centrifuge (Xiang-Yi Centrifuge Instrument Co. Ltd., Changsha, China) at 3000 revolutions per minute $(\mathrm{rpm})$ for $30 \mathrm{~min}$. The water layer formed was decanted; the residual paste was weighed and the percentage of water separated after each of the four freeze-thaw cycles was calculated as follows:

$$
\text { Syneresis }=\frac{m_{2}-m_{3}}{m_{2}-m_{1}} \times 100 \%,
$$


TABLE 1: Percent acetylation, degree substitution, and reaction efficiency of the acetylated and control (native) starch from T. leontopetaloides.

\begin{tabular}{lccr}
\hline Experiment & \% of acetyl & DS $\left(\times 10^{-4}\right)$ & RE $(\%)$ \\
\hline 0 & 0 & 0 & 0 \\
1 & $23 \pm 0.02$ & $12 \pm 0.002$ & $61.43 \pm 0.03$ \\
2 & $17 \pm 0.03$ & $35 \pm 0.001$ & $59.77 \pm 0.02$ \\
3 & $19 \pm 0.01$ & $56 \pm 0.003$ & $60.64 \pm 0.02$ \\
4 & $38 \pm 0.01$ & $81 \pm 0.001$ & $66.85 \pm 0.04$ \\
5 & $32 \pm 0.02$ & $111 \pm 0.004$ & $64.27 \pm 0.03$ \\
6 & $51 \pm 0.04$ & $151 \pm 0.002$ & $70.73 \pm 0.03$ \\
7 & $47 \pm 0.03$ & $202 \pm 0.002$ & $70.26 \pm 0.04$ \\
8 & $14 \pm 0.01$ & $243 \pm 0.004$ & $58.82 \pm 0.03$ \\
9 & $27 \pm 0.01$ & $296 \pm 0.003$ & $62.38 \pm 0.02$ \\
10 & $42 \pm 0.02$ & $366 \pm 0.001$ & $67.76 \pm 0.03$ \\
\hline
\end{tabular}

Values are expressed as SEM of 3 readings.

where $m_{1}, m_{2}$, and $m_{3}$ are, respectively, the weights in gram of centrifuge tube $(\mathrm{g})$, centrifuge tube and starch paste, and centrifuge tube and starch paste after centrifuging.

2.6. Determination of Tack Strength. Tack strength of the samples was determined according to a standard ASTM D1876 method [68]. $125 \mu \mathrm{m}$ thick wet layer of each of the eleven pastes was applied to two kraft papers measuring $15 \mathrm{~cm}$ $\times 3 \mathrm{~cm}$ with bond area of $6 \mathrm{~cm} \times 3 \mathrm{~cm}$ and the papers bonded together. The peel strength of the two bonded Kraft papers was tested by clamping one end and turning the other $180^{\circ}$ downwards and attaching a load pan to it. Standard weights were added to the load pan until the bond begins to peel. Average of three weights required for the peel to begin was recorded for each sample.

2.7. Determination of Optical Clarity. The optical clarity of the samples was determined according to a standard method [69]. Starch (0.5 g, dry weight) was suspended in distilled water $(50 \mathrm{~mL})$ in a screw cap tube and boiled for $20 \mathrm{~min}$ and the tube was thoroughly shaken every $5 \mathrm{~min}$. After cooling to room temperature $\left(33^{\circ} \mathrm{C}\right)$, the percent transmittance $(T \%)$ of each sample at $650 \mathrm{~nm}$ was determined against a water blank in UV-2102PC spectrophotometer (Unico Instruments Co. Ltd., Shanghai, China).

2.8. Determination of Viscosity. Viscosity of the pastes was determined using Brabender Visco-Amylo-Graph (BVA, A.W. Brabender Instrument Inc., South Hackensack, NJ, USA) according to ASTM D1084 standard [70].

2.9. Determination of Drying Time. A uniform $150 \mu \mathrm{m}$ thick film of each paste was cast on two glass slides with their edges tapped off with a layer of masking tape. The drying time for each paste was determined by touching the film lightly with index finger at an interval of $2 \mathrm{~min}$. The first time the film was felt to be tacky enough but do not transfer a wet film to the finger was recorded.
2.10. Determination of Gelation Time. $20 \mathrm{~g}$ of each of the nine pastes was heated at $105^{\circ} \mathrm{C}$ and cooled at room temperature $\left(33^{\circ} \mathrm{C}\right)$ and the time taken for it to form a firm gel was noted.

2.11. Statistical Analysis. Data were subjected to one-way analysis of variance (ANOVA). GraphPad Prism 5.00 software was used for all the statistical analyses.

\section{Results and Discussion}

The mean values of percent acetylation (\% acetyl), degree substitution (DS), and reaction efficiency (RE) of the acetylated starches obtained from addition of varying amounts of acetic anhydride in the 10 experiments, in comparison to the native T. leontopetaloides starch, are presented in Table 1.

As seen, higher acetyl content and DS values were found with increase in the amount of acetic anhydride, in agreement with the findings of Luo and Shi [55]. It can also be observed from the table that the values of acetyl content, degree of substitution, and reaction efficiency increase with increase in the amount of acetic anhydride (from $2.55 \mathrm{~g}$ in experiment 1 to $26.50 \mathrm{~g}$ in experiment 10). The efficiency of the acetylation process, represented by acetyl content of the esterified native starch, ranged from $0.23 \%$ (experiment 1) to $0.42 \%$ (experiment 10 ), giving an increase of $0.19 \%$. Since acetylation replaces hydrogen of the hydroxyl groups in the native starch with acetyl groups, according to Hwang [52], introduction of the acetyl groups alters the adhesive properties. He found that introduction of the acetyl group reduces bond strength with the resultant acetylated starch exhibiting improved resistance to retrogradation. The reagent used during the acetylation process must yield acceptable products and satisfy the requirement of government regulations especially when the resultant starch acetates are intended for adhesive and other nonfood uses. The extent of substitution of hydrogen atom of the hydroxyl group of the native starch for acetyl $\left(\mathrm{CH}_{3} \mathrm{CO}\right)$ functional group, represented by the degree of substitution (DS) of the ten acetylated $T$. leontopetaloides starch samples, ranged from 


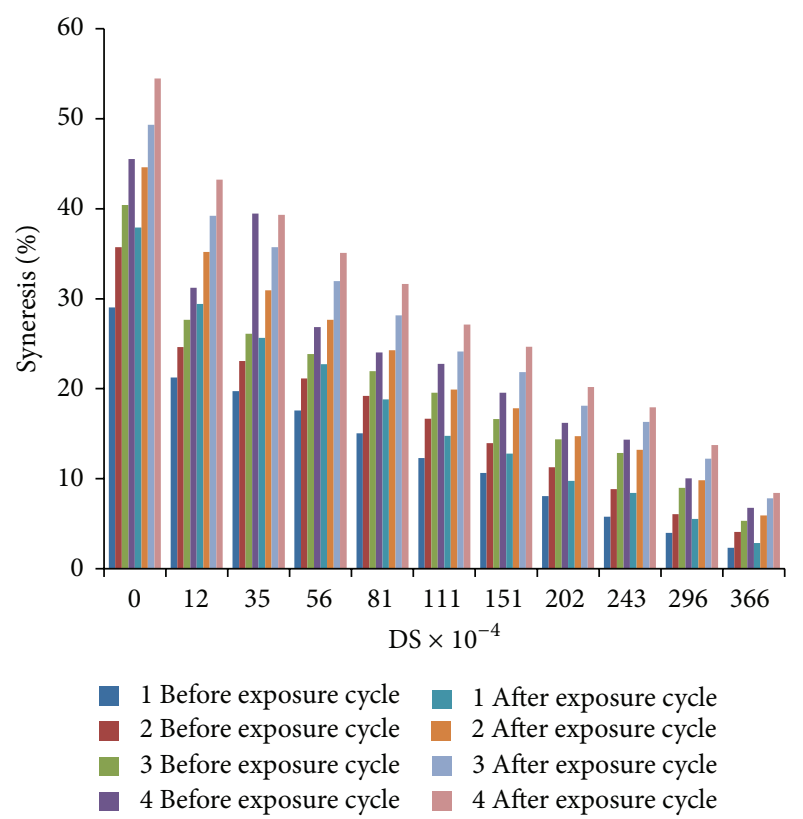

FIGURE 3: Effect of degree of substitution on the four-cycle syneresis of the samples before and after exposure to sunlight for five weeks.

0.012 (experiment 1) to 0.366 (experiment 10), an increase of 0.354 . Since the values fall within the $0.01-0.50$ range recommended by the Adhesives and Sealants Council of the USA for remoistenable adhesives, the acetylated samples are qualified for use in paper works. The relative efficiency (RE) of acetylation of the native starch values ranged from $61.43 \%$ (experiment 1) to $67.76 \%$ (experiment 10), an increase of $6.33 \%$. Utkin and associates have reported that the extent of acetylation of native starch on its key adhesive properties may vary depending on the methods and the conditions involved in the acetylation process as the method used in adding the acetylating agent may also affect the reaction leading to variation in the acetyl content and degrees of substitution (DS) and the resultant acetylated starch properties.

3.1. Syneresis. The four-cycle syneresis (amount of water seeped from or released by a paste) as a function of DS of both native and acetylated samples, before and after exposure to sunlight for five weeks, is shown in Figure 3. Overall, the syneresis values ranged from $54.47 \%$ for control after exposure in the fourth cycle to $2.33 \%$ for the sample containing $26.50 \mathrm{~g}$ acetic anhydride (highest DS of 0.366 ) before exposure in the first cycle. Considering the syneresis before exposure, it can be seen that the amount of water loss in the control sample ranged from $29.03 \%$ after the first cycle to $45.52 \%$ after fourth cycle, an increase of $16.09 \%$ in syneresis. After exposure, the amount of water loss in the control sample ranged from $37.91 \%$ after the first cycle to $54.47 \%$ after fourth cycle, an increase of $16.56 \%$. Similar trend can be observed for the acetylated samples. The inverse relation between DS and extent of syneresis can be observed in the figure for all the samples (exposed and unexposed). Before exposure, as the DS values increased from 0.012 to 0.366 , syneresis values ranged from $21.26 \%$ to $2.33 \%$ (DS 0.366 ), a decrease of $18.93 \%$.

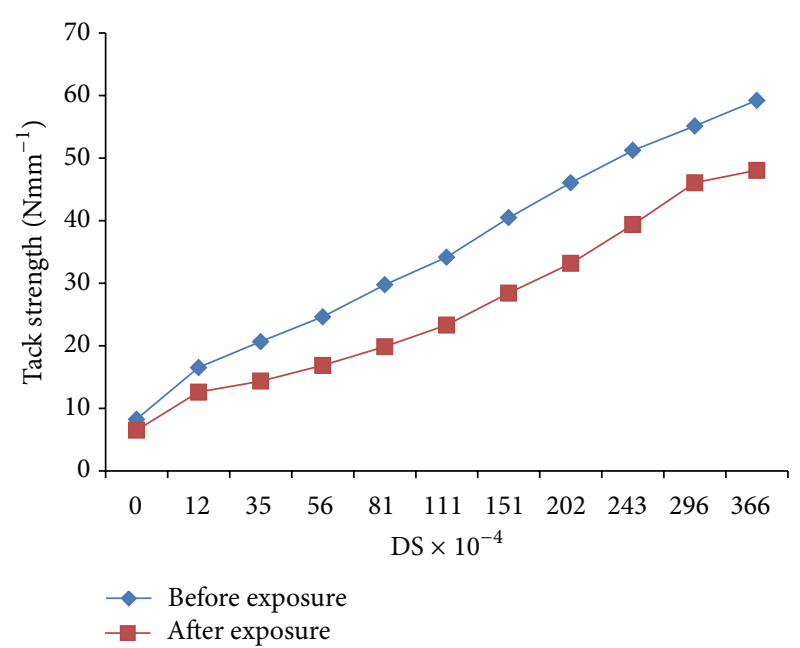

FIGURE 4: Effect of degree of substitution on tack strength of the native and acetylated starch before and after exposure to sunlight for five weeks.

Similar trend was observed after exposure although being with relatively higher syneresis values. The direct relationship between number of cycles and extent of syneresis can also be observed. As the number of cycles increases, so are the values of syneresis for all the samples (exposed and unexposed). Again, relatively higher values of syneresis are obtained after exposure. That is, for the same cycle number, there is an increase in syneresis for all sample pairs after exposure to sunlight.

Decrease in syneresis with increase in DS suggests that acetylation is a convenient way of stabilizing native starches against retrogradation, an undesirable property of adhesive pastes, especially when the samples are exposed outdoors. The decrease in syneresis with increase in DS is attributed to the higher water-holding capacity of the acetylated in comparison to the native starch. Further, there were several reports that hydrogen bonding between the aligned amylose and amylopectin polymeric chains is responsible for the retrogradation phenomenon that involves release of some loosely bound water molecules or syneresis $[33,34]$.

3.2. Tack Strength. Effect of DS on tack strength of the native and acetylated starch before and after exposure to sunlight for five weeks is shown Figure 4. Tack strength (the minimum force required for an adhesive joint to peel or the minimum weight a bonded joint can support at a particular temperature before peeling) of the samples ranged from $8.27 \mathrm{Nmm}^{-1}$ for control to $59.22 \mathrm{Nmm}^{-1}$ for the sample with highest DS before exposure and increase with increase in DS. Thus, for each 0.0037 increase in DS, there is a corresponding 4.632 increase in tack strength before exposure. After the five-week exposure period, the tack strength of the pastes ranged from $6.52 \mathrm{Nmm}^{-1}$ for native starch to $48.05 \mathrm{Nmm}^{-1}$ for the acetylated sample with the highest value of DS and increase with increase DS. Thus, for each 0.0037 increase in DS, there is a corresponding $3.775 \mathrm{Nmm}^{-1}$ increase in tack strength after the five-week exposure period. Although 


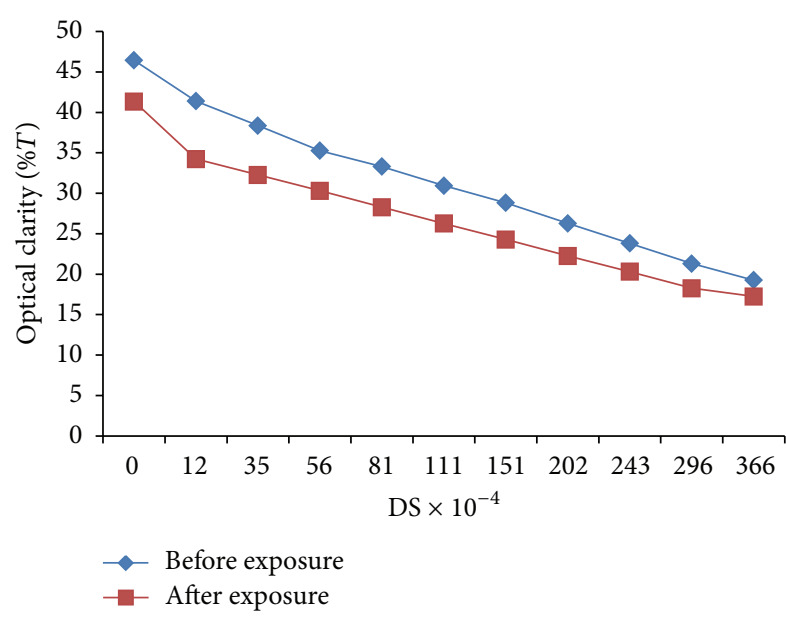

FIgURE 5: Effect of degree of substitution on optical clarity of the native and acetylated starch before and after exposure to sunlight for five weeks.

the values obtained are relatively lower than those obtained from the literature [12], they are within the recommended range for remoistenable adhesives. As tack strength is the most important property of adhesives, the modified starch paste can be used as adhesive in paper works.

Thuwall et al. and coworkers have found that intramolecular hydrogen bonding between $\mathrm{OH}-6$ and the adjacent hemiacetal oxygen atom of the D-glucopyranosyl residues and intermolecular hydrogen bonding between $\mathrm{OH}-2$ and the adjacent O-6 of the D-glucopyranosyl residues on different amylose and amylopectin molecules are responsible for the relative greater tack strength of the modified starch [15]. Lower tack strength values of exposed samples in comparison to the control samples suggest that exposure to sunlight is detrimental to both the native and acetylated starch pastes within our study period.

3.3. Optical Clarity. Optical clarity (the ease with which the pastes allow light to pass through them) of the samples that ranged from $46.44 \%$ for control to $19.26 \%$ for the sample with highest DS before exposure is shown in Figure 5. As seen, the optical clarity of the samples, before and after exposure to sunlight, decreases with increase in DS. This translates to $2.471 \%$ decrease in optical clarity for every 0.0037 increase in DS value before exposure. After the five-week exposure period, the optical clarity of the pastes ranged from $41.35 \%$ for the native starch to $17.25 \%$ for the acetylated starch with highest value of DS and also decreases with increase DS. Thus, for each 0.0037 increase in DS, there is a corresponding 2.191\% decrease in optical clarity after the five-week exposure period. Since the optical clarity of both native starch and modified starch decreases with increase in DS, the pastes are not recommended for use where transparency of the pastes is critical factor. Some researchers have reported that optical clarity of remoistenable adhesives for postage stamps must remain stable to the vagaries of weather elements, such as sunlight, heat, and moisture [11]. That is, the adhesive must not be opaque during manufacture, storage, or use.

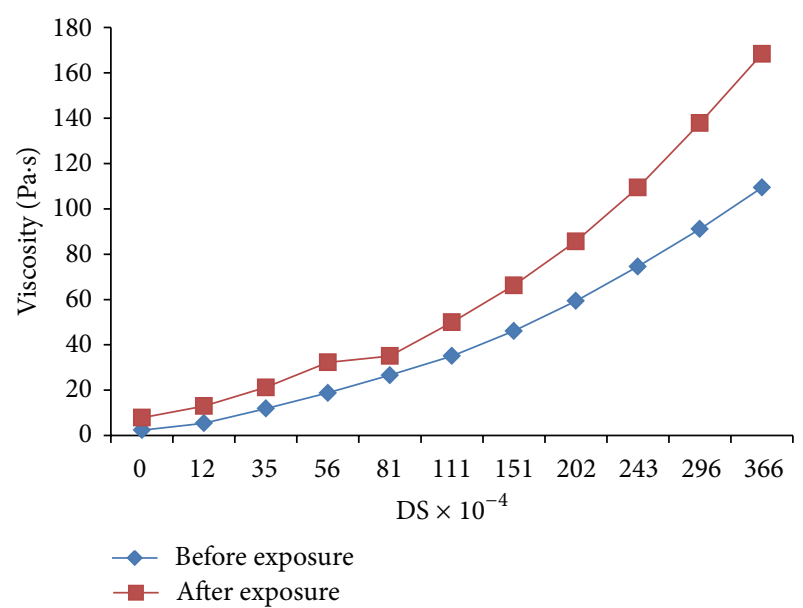

FIGURE 6: Effect of degree of substitution on viscosity of the native and acetylated starch before and after exposure to sunlight for five weeks.

3.4. Viscosity. Viscosity (the ease with which a fluid sample flows) of the eleven test pastes is shown in Figure 6. Before the five-week exposure, the viscosity of the samples ranged from 2.37 Pa.s for the native starch to 109.43 Pa.s for the most acetylated starch and can be seen to increase with increase in DS. This translates to $9.733 \mathrm{~Pa} \cdot \mathrm{s}$ increase in viscosity for every 0.0037 increase in DS. After five weeks of exposure to sunlight, the viscosity of the pastes ranged from 7.88 for the native starch to $168.33 \mathrm{~Pa} \cdot \mathrm{s}$ for the acetylated starch with highest value of DS and increases with increase in DS. Thus, for each 0.0037 increase in DS, there is a corresponding $14.586 \mathrm{~Pa} \cdot \mathrm{s}$ increase in viscosity. Going by the several literature reports [5-7] that adhesives for use in paper bags and sacks must have viscosity range of 2 to $140 \mathrm{~Pa} \cdot \mathrm{s}$ at $25^{\circ} \mathrm{C}$, those for bottle labeling (about $100 \mathrm{~Pa} \cdot \mathrm{s}$ ) and for use in envelopes ( 2 to $10 \mathrm{~Pa} \cdot \mathrm{s}$ ), the viscosity range of the acetylated samples falls within the specified range and is stable to exposure to sunlight for the period under investigation (five weeks). The stability of the acetylated samples to the retrogradation that may manifest as decrease or excessive increase in viscosity of the adhesive pastes can be seen from the figure. The increase in viscosity is gradual and steady for both the exposed and unexposed samples.

3.5. Drying and Gelation Times. The drying and gelation times of the eleven pastes are both shown in Figure 7. Drying time (the time it takes an adhesive paste applied on a substrate to completely dry) of the eleven pastes before the five weeks of exposure ranged from $4.05 \mathrm{~min}$ for the native starch to $58.43 \mathrm{~min}$ for the acetylated starch with highest value of DS and increase with increase in DS. This implies that, for each 0.0037 increase in DS, there is a corresponding $4.944 \mathrm{~min}$ increase in drying time. After five weeks of exposure to sunlight, the drying times of the pastes ranged from $2.42 \mathrm{~min}$ for the native starch to $45.21 \mathrm{~min}$ for the acetylated starch with highest value of DS and also increase with increase in DS. That is, for every 0.0037 increase in DS, a corresponding $3.890 \mathrm{~min}$ increase in drying time is obtained. The gelation 


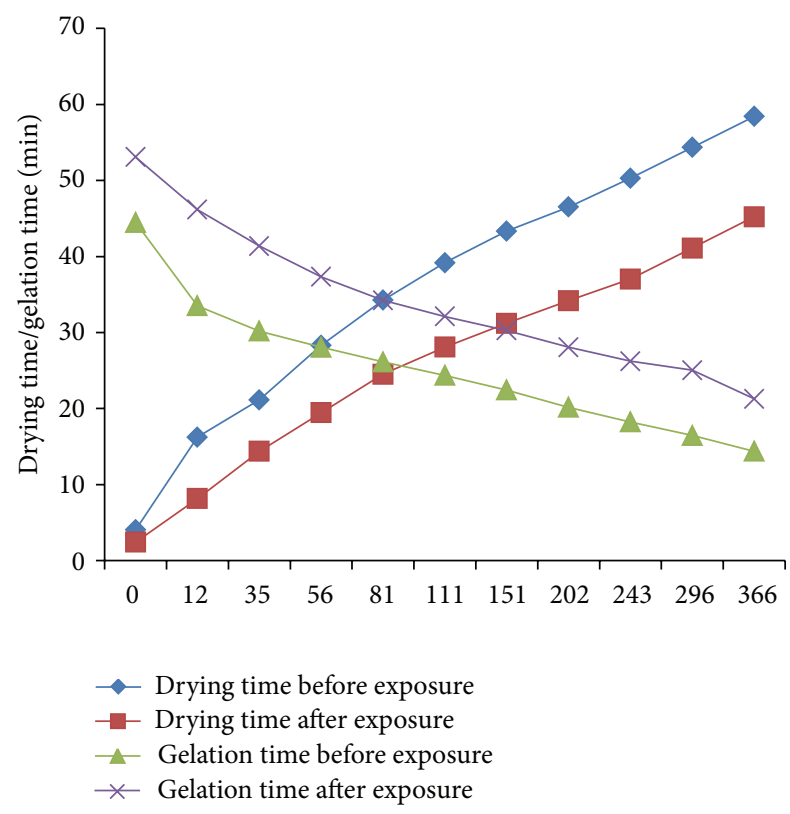

FIgURE 7: Effect of degree of substitution on drying and gelation times of the native and acetylated starch before and after exposure to sunlight for five weeks.

time (the time it takes a paste to become rigid enough to hold its shape even when cut) of both the exposed and unexposed samples is shown in Figure 5. The gelation times of the samples ranged from $44.47 \mathrm{~min}$ (control) to $14.32 \mathrm{~min}$ (the most acetylated). From the figure, it can be seen that, in contrast to drying time, gelation time decreases with increase in DS. Specifically, there is $2.741 \mathrm{~min}$ decrease in gelation time for every 0.0037 increase in DS before the samples were exposed to sunlight. After the five-week exposure period, the gelation time of the pastes ranged from $53.07 \mathrm{~min}$ for the native starch to $21.27 \mathrm{~min}$ for the acetylated starch with highest value of DS and decreases with increase DS, translating to $2.891 \mathrm{~min}$ decrease in gelation time for every 0.0037 increase in DS. These results indicate that acetylation has enhanced the suitability of the samples for adhesive use (lower drying time but longer gelation time) as earlier found by many researchers $[9,10,36]$.

\section{Conclusion}

On the basis of the results obtained in this study, it can be safely concluded that esterification of native T. leontopetaloides starch with acetic anhydride has improved its desired adhesive properties (decrease in syneresis and drying time, as well as increase in tack strength and gelation time). Although the five-week exposure period has reduced the adhesive efficiency of the acetylated starch, the reduction was not drastic enough to render it unfit for remoistenable adhesive use. Since the acetylation process has stabilized the native starch against retrogradation, the most serious problem affecting bioadhesives, that is, acetylation, is strongly recommended for value addition to the widely available and often waste starch from nonfood sources such as wild T. leontopetaloides tubers to yield acceptable adhesives that comply with economic, environment, health, and safety regulations. Also recommended is the inclusion of ultraviolet light retardants or stabilizers in formulations of bioadhesives, so that prolonged exposure to sunlight might not adversely affect the desired adhesive properties. As can be seen from the results, prolonged exposure of the samples to sunlight has increased syneresis, viscosity, and gelation time as decreased the tack strength, optical clarity, and drying time.

\section{Conflict of Interests}

The authors declare that there is no conflict of interests regarding the publication of this paper.

\section{References}

[1] J. Zalucha, "The chemistry and structure of adhesives," in Rieldel's Handbook of Industrial Chemistry, J. A. Kent, Ed., pp. 239-247, S.K. Jain Publishers, New Delhi, India, 9th edition, 1997.

[2] S. Ebnesajjad, Handbook of Adhesives and Surface Preparation: Technology, Applications and Manufacturing, Elsevier, Amsterdam, The Netherlands, 2010.

[3] K. L. Mittal and A. Pizzi, Handbook of Adhesive Technology, Marcel Dekker, New York, NY, USA, 2nd edition, 2003.

[4] H. Wiese, "Characterization of aqueous polymer dispersions," in Polymer Dispersions and Their Industrial Applications, D. Urban and K. Takamura, Eds., pp. 41-73, Wiley-VCH, Weinheim, Germany, 2002.

[5] J. Comyn, "What are adhesives and sealants and how do they work?" in Adhesive Bonding: Science, Technology and Applications, D. Adams, Ed., pp. 23-51, CRC Press, Boca Raton, Fla, USA, 2005.

[6] Y. Y. Huang, W. Zhou, K. J. Hsia et al., "Stamp collapse in soft lithography," Langmuir, vol. 21, no. 17, pp. 8058-8068, 2005.

[7] N. Maeda, N. Chen, M. Tirrell, and J. N. Israelachvili, "Adhesion and friction mechanisms of polymer-on-polymer surfaces," Science, vol. 297, no. 5580, pp. 379-382, 2002.

[8] B. K. Sharma, Industrial Chemistry, Krishna Prakashan Media (P) Limited, Meerut, India, 2011.

[9] J. Custódio, J. Broughton, and H. Cruz, "A review of factors influencing the durability of structural bonded timber joints," International Journal of Adhesion and Adhesives, vol. 29, no. 2, pp. 173-185, 2009.

[10] S. H. Yoo and J. L. Jane, "Structural and physical characteristics of waxy and other wheat starches," Carbohydrate Polymers, vol. 49, no. 3, pp. 297-305, 2002.

[11] L. A. Bello-Pérez, E. Agama-Acevedo, S. G. Sáyago-Ayerdi, E. Moreno-Damian, and J. D. C. Figueroa, "Some structural, physicochemical and functional studies of banana starches Isolated from two varieties growing in Guerrero, México," Starch/Stärke, vol. 52, no. 2-3, pp. 68-73, 2000.

[12] L. Jayakody, R. Hoover, Q. Liu, and E. Donner, "Studies on tuber starches. II. Molecular structure, composition and physicochemical properties of yam (Dioscorea sp.) starches grown in Sri Lanka," Carbohydrate Polymers, vol. 69, no. 1, pp. 148-163, 2007.

[13] J. E. McMurry, Organic Chemistry, Brooks/Cole Cengage Learning, Belmont, Calif, USA, 2012. 
[14] M. Li, P. Liu, W. Zou et al., "Extrusion processing and characterization of edible starch films with different amylose contents," Journal of Food Engineering, vol. 106, no. 1, pp. 95-101, 2011.

[15] M. Thuwall, A. Boldizar, and M. Rigdahl, "Extrusion processing of high amylose potato starch materials," Carbohydrate Polymers, vol. 65, no. 4, pp. 441-446, 2006.

[16] Y. Tian, Y. Li, X. Xu et al., "A novel size-exclusion high performance liquid chromatography (SE-HPLC) method for measuring degree of amylose retrogradation in rice starch," Food Chemistry, vol. 118, no. 2, pp. 445-448, 2010.

[17] K. Kohyama, J. Matsuki, T. Yasui, and T. Sasaki, "A differential thermal analysis of the gelatinization and retrogradation of wheat starches with different amylopectin chain lengths," Carbohydrate Polymers, vol. 58, no. 1, pp. 71-77, 2004.

[18] R. N. Waduge, R. Hoover, T. Vasanthan, J. Gao, and J. Li, “Effect of annealing on the structure and physicochemical properties of barley starches of varying amylose content," Food Research International, vol. 39, no. 1, pp. 59-77, 2006.

[19] R. M. Ward, Q. Gao, H. de Bruyn, R. G. Gilbert, and M. A. Fitzgerald, "Improved methods for the structural analysis of the amylose-rich fraction from rice flour," Biomacromolecules, vol. 7, no. 3, pp. 866-876, 2006.

[20] M. Tako and S. Hizukuri, "Rheological properties of wheat (Halberd) amylopectin," Starch/Stärke, vol. 55, no. 8, pp. 345349, 2003.

[21] M. Tako, I. Shiroma, and S. Uechi, "Rheological properties of wheat amylopectin," Science Buletin of Faculty of Agriculture, University of Ryukyus, vol. 51, pp. 139-143, 2004.

[22] D. Plackett, H. Anturi, M. Hedenqvist et al., "Physical properties and morphology of films prepared from microfibrillated cellulose and microfibrillated cellulose in combination with amylopectin," Journal of Applied Polymer Science, vol. 117, no. 6, pp. 3601-3609, 2010.

[23] D. R. Askeland and P. P. Pradeep, The Science and Engineering of Materials, Thomson Engineering, Boston, Mass, USA, 5th edition, 2005.

[24] C. Hall, Polymer Materials: An Introduction for Technologists and Scientists, Macmillan Educational, Hampshire, UK, 2008.

[25] J. Delville, C. Joly, P. Dole, and C. Bliard, "Influence of photocrosslinking on the retrogradation of wheat starch based films," Carbohydrate Polymers, vol. 53, no. 4, pp. 373-381, 2003.

[26] M. A. Ottenhof, S. E. Hill, and I. A. Farhat, "Comparative study of the retrogradation of intermediate water content waxy maize, wheat, and potato starches," Journal of Agricultural and Food Chemistry, vol. 53, no. 3, pp. 631-638, 2005.

[27] A. L. M. Smits, P. H. Kruiskamp, J. J. G. van Soest, and J. F. G. Vliegenthart, "The influence of various small plasticisers and malto-oligosaccharides on the retrogradation of (partly) gelatinised starch," Carbohydrate Polymers, vol. 51, no. 4, pp. 417-424, 2003.

[28] A. A. Karim, M. H. Norziah, and C. C. Seow, "Methods for the study of starch retrogradation," Food Chemistry, vol. 71, no. 1, pp. 9-36, 2000.

[29] Y. Tian, Y. Li, X. Xu, and Z. Jin, "Starch retrogradation studied by thermogravimetric analysis (TGA)," Carbohydrate Polymers, vol. 84, no. 3, pp. 1165-1168, 2011.

[30] M. Tako and S. Hizukuri, "Retrogradation mechanism of rice starch," Cereal Chemistry, vol. 77, no. 4, pp. 473-477, 2000.

[31] Q. Liu and D. B. Thompson, "Effects of moisture content and different gelatinization heating temperatures on retrogradation of waxy-type maize starches," Carbohydrate Research, vol. 314, no. 3-4, pp. 221-235, 1998.
[32] X. Lian, S. Zhao, Q. Liu, and X. Zhang, "A photographic approach to the possible mechanism of retrogradation of sweet potato starch," International Journal of Biological Macromolecules, vol. 48, no. 1, pp. 125-128, 2011.

[33] S. Charoenrein, O. Tatirat, and J. Muadklay, "Use of centrifugation-filtration for determination of syneresis in freeze-thaw starch gels," Carbohydrate Polymers, vol. 73, no. 1, pp. 143-147, 2008.

[34] S. Charoenrein, O. Tatirat, K. Rengsutthi, and M. Thongngam, "Effect of konjac glucomannan on syneresis, textural properties and the microstructure of frozen rice starch gels," Carbohydrate Polymers, vol. 83, no. 1, pp. 291-296, 2011.

[35] G. Wu, C. van Alsenoy, H. J. Geise et al., "Acetic anhydride in the gas phase, studied by electron diffraction and infrared spectroscopy, supplemented with ab initio calculations of geometries and force fields," Journal of Physical Chemistry A, vol. 104, no. 7, pp. 1576-1587, 2000.

[36] A. Deb, I. Malvade, P. Biswas, and J. Schroeder, "An experimental and analytical study of the mechanical behaviour of adhesively bonded joints for variable extension rates and temperatures," International Journal of Adhesion and Adhesives, vol. 28, no. 1-2, pp. 1-15, 2008.

[37] C. E. Carraher Jr., Introduction to Polymer Chemistry, CRC Press, Boca Raton, Fla, USA, 2nd edition, 2010.

[38] E. Johansson, L. Lundström, M. Norgren, and L. Wågberg, "Adsorption behavior and adhesive properties of biopolyelectrolyte multilayers formed from cationic and anionic starch," Biomacromolecules, vol. 10, no. 7, pp. 1768-1776, 2009.

[39] H. R. Allock, Introduction to Materials Chemistry, John Wiley \& Sons, Singapore, 2008.

[40] L. S. Collado, R. C. Mabesa, and H. Corke, "Genetic variation in the physical properties of sweet potato starch," Journal of Agricultural and Food Chemistry, vol. 47, no. 10, pp. 4195-4201, 1999.

[41] D. R. Lu, C. M. Xiao, and S. J. Xu, "Starch-basedcompletely biodegradable polymer materials," Express Polymer Letters, vol. 3, no. 6, pp. 366-375, 2009.

[42] X. Y. Song, G. Q. He, H. Ruan, and Q. H. Chen, "Preparation and properties of octenyl succinic anhydride modified early Indica rice starch," Starch/Stärke, vol. 58, no. 2, pp. 109-117, 2006.

[43] S. Saartratra, C. Puttanlekb, V. Rungsardthong, and D. Uttapap, "Paste and gel properties of low-substituted acetylated canna starches," Carbohydrate Polymers, vol. 61, no. 2, pp. 211-221, 2005.

[44] S. J. Gao and K. Nishinari, "Effect of degree of acetylation on gelation of konjac glucomannan," Biomacromolecules, vol. 5, no. 1, pp. 175-185, 2004.

[45] Y. Xu, V. Miladinov, and M. A. Hanna, "Synthesis and characterization of starch acetates with high substitution," Cereal Chemistry, vol. 81, no. 6, pp. 735-740, 2004.

[46] S. Richardson and L. Gorton, "Characterisation of the substituent distribution in starch and cellulose derivatives," Analytica Chimica Acta, vol. 497, no. 1-2, pp. 27-65, 2003.

[47] R. N. Waduge, R. Hoover, T. Vasanthan, J. Gao, and J. Li, "Effect of annealing on the structure and physicochemical properties of barley starches of varying amylose content," Food Research International, vol. 39, no. 1, pp. 59-77, 2006.

[48] K. M. Chung, T. W. Moon, and J. K. Chun, "Influence of annealing on gel properties of Mung bean starch," Cereal Chemistry, vol. 77, no. 5, pp. 567-571, 2000. 
[49] R. F. Tester and S. J. J. Debon, "Annealing of starch-a review," International Journal of Biological Macromolecules, vol. 27, no. 1, pp. 1-12, 2000.

[50] C. Pukkahuta and S. Varavinit, "Structural transformation of sago starch by heat-moisture and osmotic-pressure treatment," Starch/Stärke, vol. 59, no. 12, pp. 624-631, 2007.

[51] R. V. Manek, O. O. Kunle, M. O. Emeje et al., "Physical, thermal and sorption profile of starch obtained from Tacca leontopetaloides," Starch/Stärke, vol. 57, no. 2, pp. 55-61, 2005.

[52] C. S. Hwang, A. Shemorry, and A. Varshavsky, "N-terminal acetylation of cellular proteins creates specific degradation signals," Science, vol. 327, no. 5968, pp. 973-977, 2010.

[53] A. Y. Utkin, L. Y. Bogel'fer, and A. L. Chimishkyan, "Reversible reactions in the acidolysis of methyoxyacetic acid by acetic anhydride," Russian Journal of Physical Chemistry, vol. 65, pp. 1049-1059, 1991.

[54] J. J. Shatynski and D. Hanesian, "Adiabatic kinetic studies of the cytidine/acetic anhydride reaction by utilizing temperature versus time data," Industrial and Engineering Chemistry Research, vol. 32, no. 4, pp. 594-599, 1993.

[55] Z. G. Luo and Y. C. Shi, "Preparation of acetylated waxy, normal, and high-amylose maize starches with intermediate degrees of substitution in aqueous solution and their properties," Journal of Agriculture and Food Chemistry, vol. 60, no. 37, pp. 9468-9475, 2012.

[56] F. Han, C. Gao, M. Liu, F. Huang, and B. Zhang, "Synthesis, optimization and characterization of acetylated corn starch with the high degree of substitution," International Journal of Biological Macromolecules, vol. 59, pp. 372-376, 2013.

[57] S. I. Ofoefule, A. C. Osuji, and O. Okorie, "Effects of physical and chemical modifications on the disintegrant and dissolution properties of Tacca involucrata starch," Bio-Research, vol. 2, no. 1, pp. 97-102, 2004.

[58] S. Ahemen and A. O. Raji, "Development and performance evaluation of a motorized rasping machine for Tacca involucrata starch production," Journal of Agricultural Engineering and Technology, vol. 16, no. 1, pp. 52-63, 2008.

[59] A. B. Adebiyi, M. O. Omojola, A. T. Orishadipe, M. O. Afolayan, and D. Olalekan, "Tacca starch citrate-a potential pharmaceutical excipient," Archives of Applied Science Research, vol. 3, no. 6, pp. 114-121, 2011.

[60] M. Arbonnier, Trees, Shrubs and Lianas of West African Dry Zones, CIRAD, Margraf Publishers, Paris, France, 2004.

[61] O. O. Kunle, Y. E. Ibrahim, M. O. Emeje, S. Shaba, and Y. Kunle, "Extraction, physicochemical and compaction properties of tacca starch-a potential pharmaceutical excipient," Starch/Stärke, vol. 55, no. 7, pp. 319-325, 2003.

[62] U. J. Ukpabi, E. Ukenye, and A. O. Olojede, "Raw materials potentials of Nigerian wild Polynesian arrowroot (Tacca leontopetaloides) tubers and starch," Journal of Food Technology, vol. 7, no. 4, pp. 135-138, 2009.

[63] A. Rudin, Elements of Polymer Science and Engineering, Elsevier, Singapore, 2nd edition, 2006.

[64] C. M. Stafford, B. D. Vogt, C. Harrison, D. Julthongpiput, and R. Huang, "Elastic moduli of ultrathin amorphous polymer films," Macromolecules, vol. 39, no. 15, pp. 5095-5099, 2006.

[65] J. E. Braddy, N. D. Jerspersen, and A. Hyslop, Chemistry, John Wiley \& Sons, Singapore, 6th edition, 2012.

[66] L. A. Bello-Pérez, E. Agama-Acevedo, S. G. Sáyago-Ayerdi, E. Moreno-Damian, and J. D. C. Figueroa, "Some structural, physicochemical and functional studies of banana starches isolated from two varieties growing in Guerrero, México," Starch/Stärke, vol. 52, no. 2-3, pp. 68-73, 2000.

[67] L. Brown and T. Holme, Chemistry for Engineering Students, Brooks/Cole, Cengage Learning, Belmont, Calif, USA, 2nd edition, 2011.

[68] Anonymous, "Standard test method for peel resistance of adhesives," in Annual Book of ASTM Standards, (ASTM D1876), pp. 189-197, American Society for Testing and Materials, Philadelphia, Pa, USA, 2009.

[69] M. G. D. Baumann and A. H. Conner, "Carbohydrate polymers as adhesives," in Handbook of Adhesive Technology, A. Pizzi and K. L. Mittal, Eds., pp. 375-379, Marcel Dekker, New York, NY, USA, 2nd edition, 2003.

[70] Anonymous, "Standard test method for viscosity of adhesives," in Annual Book of ASTM Standards, (ASTM D1084), pp. 549557, American Society for Testing and Materials, Philadelphia, Pa, USA, 2006. 

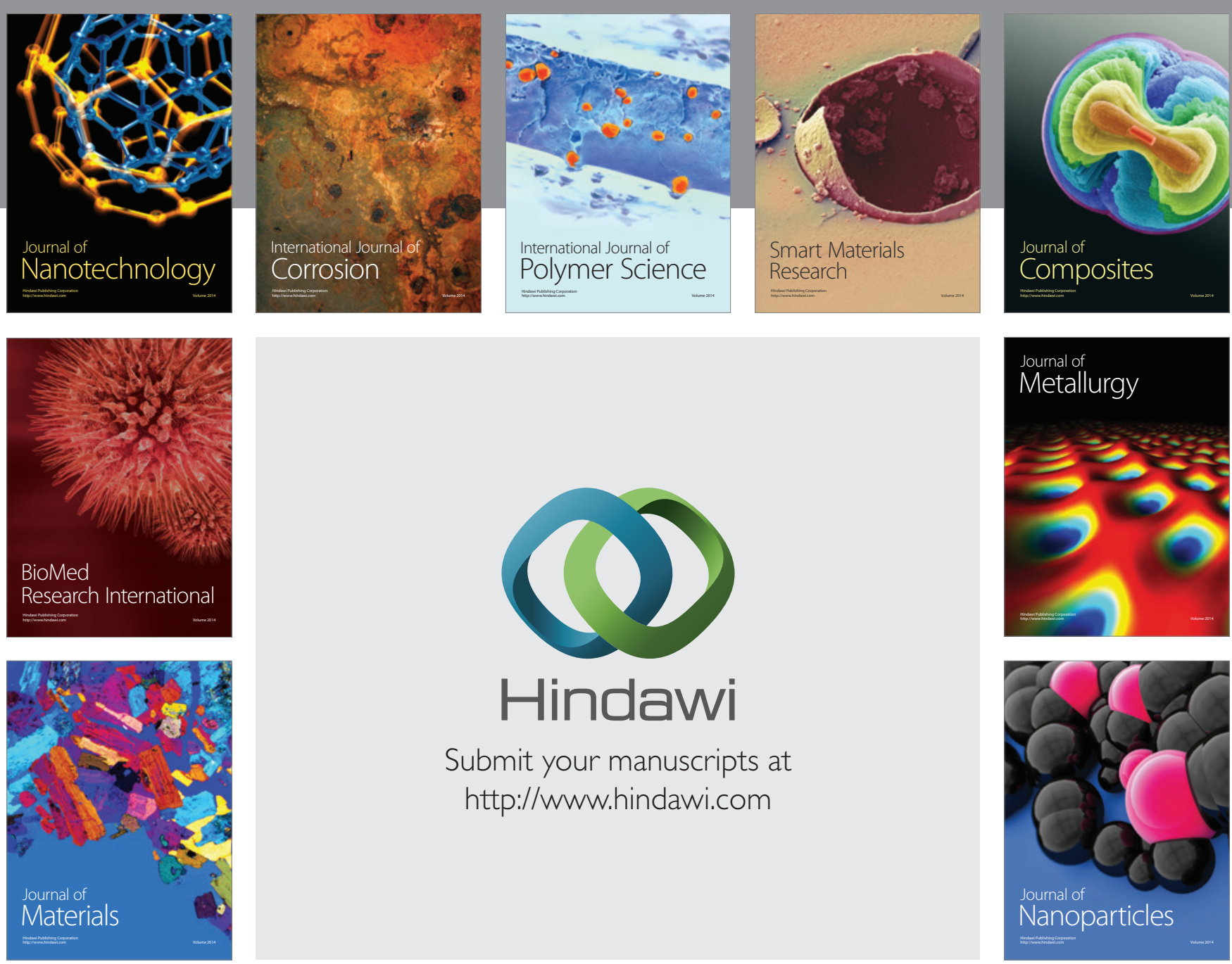

Submit your manuscripts at http://www.hindawi.com
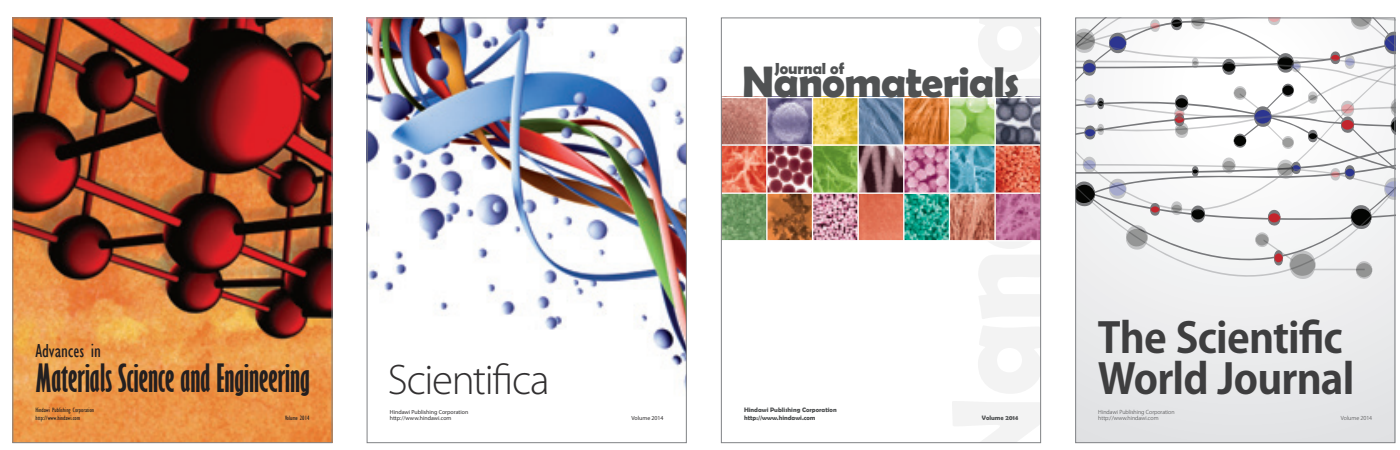

\section{The Scientific World Journal}
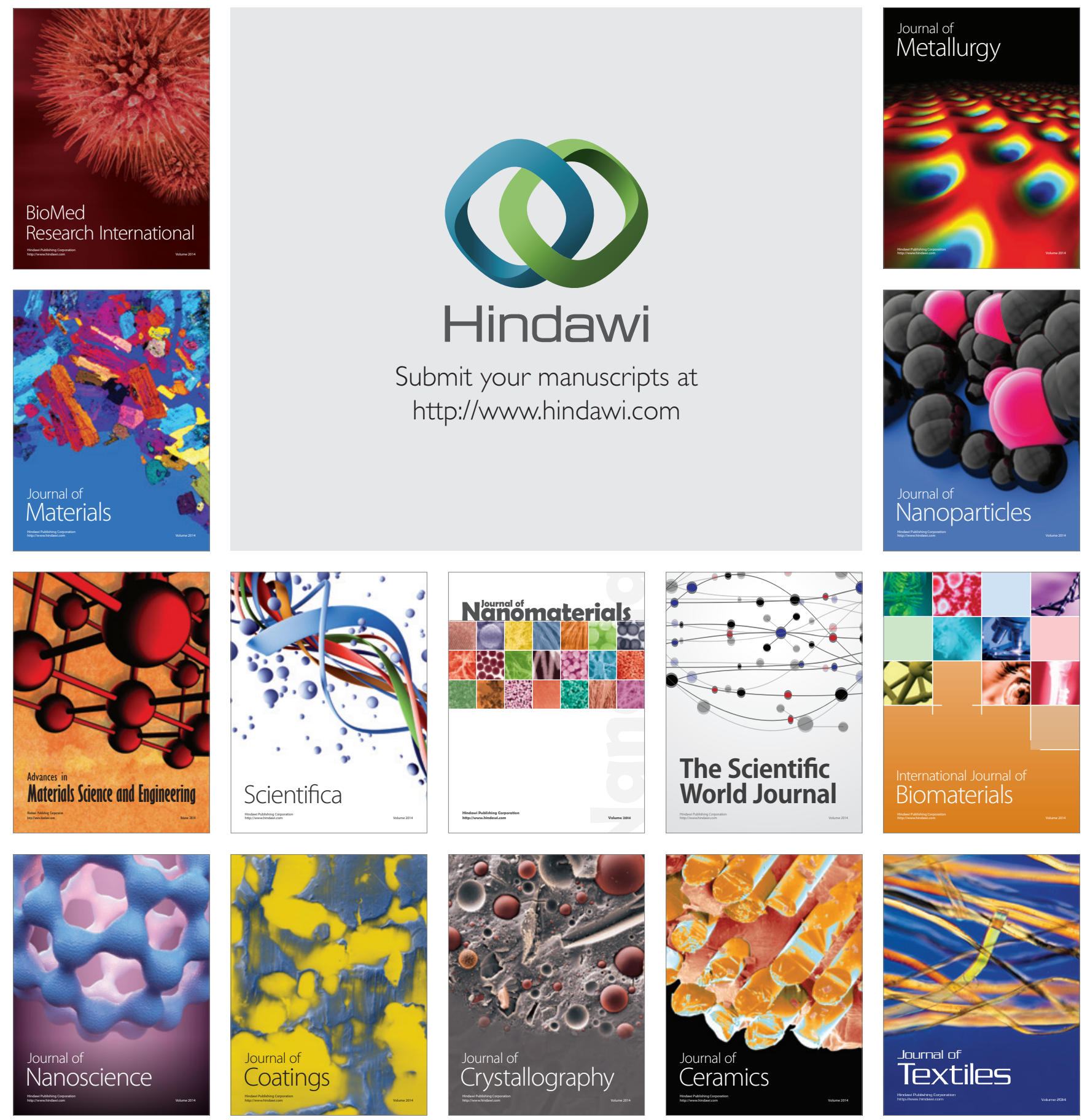